\title{
Artificial stone-associated silicosis: a rapidly emerging occupational lung disease
}

\author{
Ryan F Hoy, ${ }^{1}$ Timothy Baird, ${ }^{2}$ Gary Hammerschlag, ${ }^{3}$ David Hart, ${ }^{4}$ Anthony R Johnson, ${ }^{5}$ \\ Paul King, ${ }^{6}$ Michael Putt, ${ }^{2}$ Deborah $\mathrm{H}$ Yates ${ }^{7}$
}

'Department of Epidemiology and Preventive Medicine, School of Public Health and Preventive Medicine, Monash University, Melbourne, Victoria, Australia ${ }^{2}$ Department of Respiratory Medicine, Nambour General Hospital, Nambour, Queensland, Australia

${ }^{3}$ Department of Respiratory Medicine, Royal Melbourne Hospital, Melbourne, Victoria, Australia

${ }^{4}$ Department of Respiratory Medicine, St Vincent's Hospital, Melbourne, Victoria, Australia ${ }^{5}$ Department of Thoracic Medicine, Liverpool Hospital, Sydney, New South Wales, Australia

${ }^{6}$ Department of Respiratory Medicine, Monash Medical Centre/ Monash University, Clayton, Victoria, Australia Department of Thoracic Medicine, St Vincent's Hospital, Sydney, New South Wales, Australia

\section{Correspondence to} Dr Ryan F Hoy, Department of Epidemiology and Preventive Medicine, School of Public Health and Preventive Medicine, Monash University, Melbourne Victoria 3004, Australia; DrRyanHoy@gmail.com

Received 14 March 2017 Revised 31 July 2017 Accepted 13 August 2017 Published Online First 7 September 2017

\section{Linked}

- http://dx.doi.org/10.1136/ oemed-2017-104731

\section{CrossMark}

To cite: Hoy RF, Baird T,

Hammerschlag $\mathrm{G}$, et al.

Occup Environ Med

2018;75:3-5.

\section{ABSTRACT}

Introduction Artificial stone is an increasingly popular material used to fabricate kitchen and bathroom benchtops. Cutting and grinding artificial stone is associated with generation of very high levels of respirable crystalline silica, and the frequency of cases of severe silicosis associated with this exposure is rapidly increasing.

Aim To report the characteristics of a clinical series of Australian workers with artificial stone-associated silicosis.

Methods Respiratory physicians voluntarily reported cases of artificial stone-associated silicosis identified in their clinical practices. Physicians provided information including occupational histories, respiratory function tests, chest radiology and histopathology reports, when available.

Results Seven male patients were identified with a median age of 44 years (range 26-61). All were employed in small kitchen and bathroom benchtop fabrication businesses with an average of eight employees (range 2-20). All workplaces primarily used artificial stone, and dust control measures were poor. All patients were involved in dry cutting artificial stone. The median duration of exposure prior to symptoms was 7 years (range 4-10). Six patients demonstrated radiological features of progressive massive fibrosis. These individuals followed up over a median follow-up period of 16 months (IQR 21 months) demonstrated rapid decline in prebronchodilator forced expiratory volume in $1 \mathrm{~s}$ of $386 \mathrm{~mL} /$ year (SD $204 \mathrm{~mL}$ ) and forced vital capacity of $448 \mathrm{~mL} /$ year (SD $312 \mathrm{~mL}$ ).

Conclusions This series of silicosis in Australian workers further demonstrates the risk-associated highsilica content artificial stone. Effective dust control and health surveillance measures need to be stringently implemented and enforced in this industry.

\section{BACKGROUND}

Artificial stone (also referred to as engineered, agglomerated or reconstituted stone and quartz conglomerate) is an increasingly popular and relatively new building material used primarily in the fabrication of kitchen and bathroom benchtops. Artificial stone is manufactured by many companies worldwide. Slabs of stone are formed by mixing finely crushed rock with a polymeric resin, then moulded into slabs and heat-cured. The silica content of artificial stone is approximately $90 \%$, far higher than natural stones (marble 3\%, granite 30\% on average). ${ }^{1}$
What this paper adds

- Fabrication of benchtops from artificial stone may result in workers being exposed to high levels of respirable crystalline silica.

- The frequency of reported cases of silicosis associated with artificial stone work is increasing significantly.

- Artificial stone-associated silicosis is characterised by a shorter latency and more rapid loss of lung function than chronic silicosis.

- More cases of silicosis are likely to be diagnosed, and urgent action is required to increase awareness of the risk of silicosis in the benchtop fabrication industry. Better measures are needed to control dust levels, monitor and protect workers in this industry.

Artificial stone is then sold to benchtop fabricators, who use slabs to create benchtops based on client specifications. Crystalline silica in artificial stone becomes respirable when workers cut and grind this using powerful tools. There is little published information regarding levels of respirable crystalline silica (RCS) generated from this process. One study investigating the effectiveness of dust suppression measures when cutting artificial stone using a hand-operated circular saw noted that dry cutting generated an extremely high RCS concentration of $44 \mathrm{mg} / \mathrm{m}^{3}$ over a $30 \mathrm{~min}$ sampling period. This compares with $4.9 \mathrm{mg} / \mathrm{m}^{3}$ with wet blade cutting and $0.6 \mathrm{mg} / \mathrm{m}^{3}$ with wet blade cutting in combination with local exhaust ventilation. ${ }^{2}$ Short-term exposure to high concentrations of RCS $\left(>2 \mathrm{mg} / \mathrm{m}^{3}\right)$ has an effect three times as great as a cumulative equivalent longer term exposure to lower levels. ${ }^{3}$ Freshly created dry, very fine silica particles produced by high-energy cutting have also been demonstrated to have greater fibrogenicity compared with wet cutting of aged quartz, due to reactive free radical species forming on the surface of the particles. ${ }^{4}$

Artificial stone became commercially available in 1986, and the first report of artificial stone-associated silicosis at a stonemasonry company was published from Italy in $2010 .^{5}$ Since that time, there have been an increasing number of cases reported from Spain, Israel and the USA. ${ }^{6-9}$ A 2011 Italian study of a workshop using mainly artificial stone reported silicosis with a prevalence of $54.5 \%$ (6 out 11 workers). ${ }^{8}$ The risk of silicosis appears greatest 
when dry cutting and polishing are performed. However, cases have also been noted to occur in workplaces where water jet cutting and water dust suppression are used. ${ }^{6-8}$ Silicosis has been reported in workers involved in both workshop and home installation activities. ${ }^{8}$ Small businesses are frequently represented, and inadequacies in performance of periodic preventive medical examinations have been noted. ${ }^{7}$ Artificial stone has been available in Australia since the early 2000s. Here, we report the seven initial cases of silicosis associated with this material in Australia.

\section{METHODS}

Following the first reported case of artificial stone-associated silicosis in Australia, further cases were notified voluntarily to the Thoracic Society of Australia and New Zealand's Occupational Lung Disease Special Interest Group. ${ }^{10}$ Notifying respiratory physicians were requested to provide information including occupational histories, respiratory function tests, chest radiology and histopathology reports, when available.

The diagnosis of silicosis was based on a history of sufficient occupational silica exposure, radiological features consistent with silicosis and lung histopathology (when available) demonstrating features of silicosis. Cases were diagnosed according to recommended guidelines. Workplace exposure monitoring was unfortunately not available.

\section{RESULTS}

Between 2011 and 2016, seven cases of artificial stone-associated silicosis were identified by respiratory physicians in Queensland, ${ }^{1}$ Victoria $^{3}$ and New South Wales. ${ }^{3}$ All cases were male with a median age of 44 years (range 26-61 years). Twenty-eight per cent were non-smokers.

All the individuals were employed in small kitchen and bathroom benchtop fabrication businesses, with an average of eight employees (range 2-20). Artificial stone was the primary material used at all workplaces. Three workers were qualified stonemasons and the other four were overseas-born, from non-English-speaking backgrounds and had no formal stonemasonry training.

As part of their work duties, all men performed dry cutting of artificial stone, primarily using hand tools. Water dust suppression, if used, was typically during polishing activities or when table saws were used. Ventilation at these workplaces typically relied on ceiling extraction fans or passive airflow through open doors or windows. Only three cases were provided respiratory protection and generally in the form of disposable masks. None of the cases reported provision of education regarding respirator usage or had been involved in employer-organised health surveillance.

The median duration of exposure to artificial stone-associated dust prior to symptoms was 7.3 years (range 4-10 years). All workers presented with symptoms of cough and progressively worsening shortness of breath on exertion. The duration of symptoms prior to presentation to a respiratory physician ranged from 6 months to 3 years. One patient also noted weight loss and one experienced haemoptysis.

CT was performed in all cases. In two cases the predominant radiological finding was semiconfluent nodules in the mid and upper zones, maximal at apices and increased upper lobe interstitial markings. Extensive faint ground glass nodules were present in two cases. Six cases with severe radiological abnormalities were characterised by bilateral upper lobe fibrosis and volume loss with reticulonodular and large confluent mass-like densities, consistent with progressive massive fibrosis (PMF). One case demonstrated rapid radiological progression over a period of 4 years.

Lung biopsies were performed in five patients (four via video-assisted thoracic surgery and one cryoprobe biopsy). The predominant histological finding was a histiocytic inflammatory infiltrate. Sclerotic nodules surrounded by histiocytes and histiocytic aggregates with nodular areas were reported. In three cases, the presence of birefringent particles within some histiocytes was noted. Three patients had bronchoalveolar lavage performed with a cell differential lymphocyte percentage ranging from $31 \%$ to $54 \%$.

Respiratory function tests primarily demonstrated restrictive spirometry patterns (table 1). Over a median follow-up period of 16 months (IQR 21.25), the mean decline in prebronchodilator forced expiratory volume in $1 \mathrm{~s}\left(\mathrm{FEV}_{1}\right)$ was $386 \mathrm{~mL} /$ year (SD $204 \mathrm{~mL}$ ) and forced vital capacity was $448 \mathrm{~mL} /$ year (SD $312 \mathrm{~mL}$ ). One patient eventually underwent double lung transplantation due to severe respiratory impairment.

\section{DISCUSSION}

The characteristics of the silicosis cases reported in this series are similar to those reported internationally. The duration of occupational exposure to artificial stone-derived silica (4-10 years) is significantly shorter than with chronic silicosis in other industries. ${ }^{11}$ All workers reported performing dry cutting without provision of adequate ventilation or respiratory protection, certainly resulting in high-level RCS exposure. Six of the seven cases presented with severe lung function impairment and radiological features of PMF. None of the workers underwent

\begin{tabular}{|c|c|c|c|c|}
\hline 2 & Restrictive defect (FVC 49\%), reduced gas transfer (DLCO $41 \%$ ) & 994 & 788 & 14 \\
\hline 3 & $\begin{array}{l}\text { Mixed obstructive/restrictive defect ( } \mathrm{FEV}, 47 \%, \mathrm{FVC} 55 \%) \text {, reduced gas } \\
\text { transfer (DLCO } 53 \% \text { ) }\end{array}$ & 260 & 250 & 47 \\
\hline 5 & Restrictive defect (FVC 62\%), reduced gas transfer (DLCO 65\%) & 333 & 413 & 18 \\
\hline 6 & Mixed obstructive/restrictive defect (FEV $153 \%$, FVC $71 \%$ ) & Not available & Not available & 0 \\
\hline 7 & Restrictive defect (FVC $54 \%$ ), reduced gas transfer (DLCO $31 \%$ ) & 171 & 171 & 7 \\
\hline
\end{tabular}


employer-organised health surveillance that is designed to detect features of disease at a much earlier stage.

Our cases have demonstrated progressive disease consistent with the accelerated form of silicosis. ${ }^{9}$ The rate of decline in lung function observed has been rapid, with a mean decline in $\mathrm{FEV}_{1}$ of $386 \mathrm{~mL} /$ year (range 171-788 mL) compared with an expected rate of $36 \mathrm{~mL} /$ year. $^{12}$ Where available, bronchoalveolar lavage demonstrated lymphocytosis (31\%-54\%, normal 10\%-15\% of cellular elements) suggestive of an inflammatory process and increased risk of progression. ${ }^{9}$

Israel, a country that has used artificial stone for approximately 15 years longer than Australia, has experienced a rapidly increasing burden of associated silicosis. A total of 193 cases were reported between 2009 and 2014, and between 1997 and $2012,4 \%$ of lung transplants were performed for artificial stone-associated silicosis. There are likely to be many unidentified cases of silicosis. Genetic susceptibility appears to have little role in the development of silicosis; therefore, other workers who have experienced similar working conditions are at high risk of disease. Health surveillance is recommended for workers exposed to RCS as individuals with simple silicosis are asymptomatic and early identification is required to minimise the potential severity of disease.

While exposure control is a key preventative measure against silicosis, the differing composition of materials and working practices within this industry may require a new approach. The current Australian RCS exposure standard is $0.1 \mathrm{mg} / \mathrm{m}^{3} 8$-hour time-weighted average. In 2016, the US Occupational Safety and Health Administration (OSHA) reduced the permissible exposure limit to $0.05 \mathrm{mg} / \mathrm{m}^{3}$, acknowledging that the previous $0.1 \mathrm{mg} / \mathrm{m}^{3}$ level was associated with significant risk to health. This 8-hour standard does not provide guidance related to the risk associated with high-intensity, short-duration exposures, such as dry cutting artificial stone.

There is no proven treatment for silicosis other than lung transplantation. Thus, prevention of this disease through control of RCS dust exposure is vital. Further awareness of the risk associated with fabrication work using artificial stone is urgently required, especially at an industry level. OSHA has recently published industry-focused guidance regarding hazard mitigation strategies (available at https://www.cdc.gov/niosh/docs/ 2015-106/). In the Australian context, we believe that significantly more work is needed regarding control of exposure to RCS and health surveillance in order to protect workers in this industry.

Contributors All listed authors contributed to the development of the manuscript, identification and revision of case data and review of final manuscript.

Competing interests None declared.

Provenance and peer review Not commissioned; externally peer reviewed.

(c) Article author(s) (or their employer(s) unless otherwise stated in the text of the article) 2018. All rights reserved. No commercial use is permitted unless otherwise expressly granted.

\section{REFERENCES}

1 Ophir N, Shai AB, Alkalay Y, et al. Artificial stone dust-induced functional and inflammatory abnormalities in exposed workers monitored quantitatively by biometrics. ERJ Open Res 2016:2:00086-2015.

2 Cooper JH, Johnson DL, Phillips ML. Respirable silica dust suppression during artificial stone countertop cutting. Ann Occup Hyg 2015;59:122-6.

3 Buchanan D, Miller BG, Soutar CA. Quantitative relations between exposure to respirable quartz and risk of silicosis. Occup Environ Med 2003;60:159-64.

4 Meldrum M, Howden P. Crystalline silica: variability in fibrogenic potency. Ann occup Hyg 2002:46:27-30.

5 Martínez C, Prieto A, García L, et al. Silicosis: a disease with an active present. Arch Bronconeumol 2010;46:97-100.

6 Kramer MR, Blanc PD, Fireman E, et al. Artificial stone silicosis (corrected): disease resurgence among artificial stone workers. Chest 2012;142:419-24.

7 Pérez-Alonso A, Córdoba-Doña JA, Millares-Lorenzo JL, et al. Outbreak of silicosis in Spanish quartz conglomerate workers. Int J Occup Environ Health 2014;20:26-32.

8 Pascual S, Urrutia I, Ballaz A, et al. Prevalence of silicosis in a marble factory after exposure to quartz conglomerates. Arch Bronconeumol 2011;47:50-1.

9 Paolucci V, Romeo R, Sisinni AG, et al. Silicosis in workers exposed to artificial quartz conglomerates: does it differ from chronic simple silicosis? Arch Bronconeumol 2015:51:e57-60.

10 Frankel A, Blake L, Yates D. Complicated silicosis in an Australian worker from cutting engineered stone: an embarrassing first for Australia. Eur Respir J 2015:46:PA1144.

11 Leung CC, Yu IT, Chen W. Silicosis. Lancet 2012;379:2008-18.

12 James AL, Palmer LJ, Kicic E, et al. Decline in lung function in the Busselton Health Study: the effects of asthma and cigarette smoking. Am J Respir Crit Care Med 2005;171:109-14. 